\title{
Residual Strains of Filter Materials Reinforced with Grid Inclusions under Cyclic Loading
}

\author{
Y. L. Lin, ${ }^{\mathrm{a}, 1}$ X. X. Li, ${ }^{\mathrm{b}}$ and J. Zhang ${ }^{\mathrm{a}}$ \\ a Department of Civil Engineering, Shanghai University, Shanghai, China \\ b Shanghai Tunnel Engineering and Rail Transit Design \& Research Institute, Shanghai, China \\ ${ }^{1}$ lin_yliang@163.com
}

Reinforcement technology is widely used for filter dams in high-seismicity zones. The effect of reinforcement on deformation and safety is evaluated, and it is one of the primary objectives to be investigated in filter engineering. Residual strains of reinforced filter materials were experimentally studied using a triaxial apparatus. The effect of reinforcement mesh sizes, confining pressures, and cyclic loading modes on residual strains was analyzed. The results show that the reinforcement reduces residual strains of filter materials. Both residual shear and volume strains are determined. Based on the test results, one of the possible mechanisms of the reinforcement effect on residual strains is proposed..

Keywords: residual strain, reinforced filter material, triaxial test, cyclic loading.

Introduction. Rock-fill dams are constructed using granular material. Therefore, long-term satisfactory performance of these structures depend, in part, on the dynamic loading response of the granular materials. Improvement of the latter can be obtained by several methods, including reinforcement of the aggregate support profile, whereas geotextile is one of the most common geosynthetic materials used for soil reinforcement. Several investigations have been conducted on granular soils reinforced with a geotextile, which were mainly related to static mechanical properties of various types of reinforcement [1-4]. Many researchers have studied the liquefaction resistance of different types of materials [5-7]. However, only few studies have been made on residual strains in the reinforced filter materials.

The reinforcement techniques have been widely adopted in modern aseismic design of high dams. Nevertheless, estimation of the reinforcement effects in an aseismic design has become a crucial problem. In the aseismic design of earth structures, the emphasis has shifted from evaluating the safety factor towards reliable estimation of the residual strain. In this study, several series of dynamic triaxial tests are carried out on saturated reinforced filter materials by applying a regular cyclic excitation. The residual shear strains and volume changes during the dynamic excitation are observed, the mechanical prperties and residual strain behavior of filter materials with grid inclusions are evaluated.

Experimental Program and Procedures.

Materials. The filter material used in this tudy was obtained from the construction site of Lianghekou, China. The grain size distribution is shown in Fig. 1. The index properties of the filter materials are listed in Table 1. Figure 2 depicts the reinforcement geometry. The reinforcement used in the tests is a steel mesh with a diameter of $90 \mathrm{~mm}$, which was consructed by welding of 16 transverse and longitudinal steel rods with a diameter of $3 \mathrm{~mm}$. The width of each mesh is $10 \mathrm{~mm}$.

Triaxial Test Preparation. Triaxial tests are conducted using a static-dynamic dualpurpose triaxial compression test apparatus, in order to study the influence of reinforcement on the residual strains (Fig. 3). This device can provide many complicated stress conditions such as rotation of the principal stress axis, sand liquefaction, and simulation of earthquake- 
$\mathrm{T}$ a b 1 e 1

\section{Properties of the Filter specimen}

\begin{tabular}{||l|l||}
\hline \multicolumn{1}{|c|}{ Parameter } & Value \\
\hline Specific gravity of solids $G_{S}$ & 2.7 \\
\hline Maximum unit weight $\left(\mathrm{kN} / \mathrm{m}^{3}\right)$ & 21.4 \\
\hline Minimum unit weight $\left(\mathrm{kN} / \mathrm{m}^{3}\right)$ & 17.8 \\
\hline Relative density $(\%)$ & 0.4 \\
\hline Coefficient of uniformity $C_{u}$ & 18.4 \\
\hline Coefficient of curvature $C_{c}$ & 0.54 \\
\hline
\end{tabular}

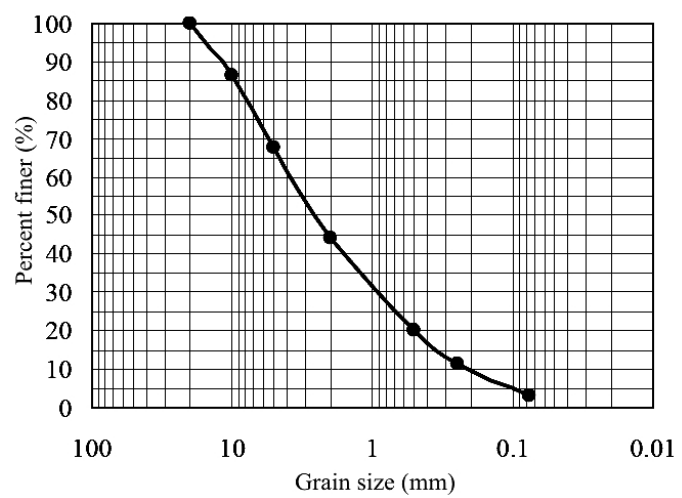

Fig. 1. Particle size distribution curve.

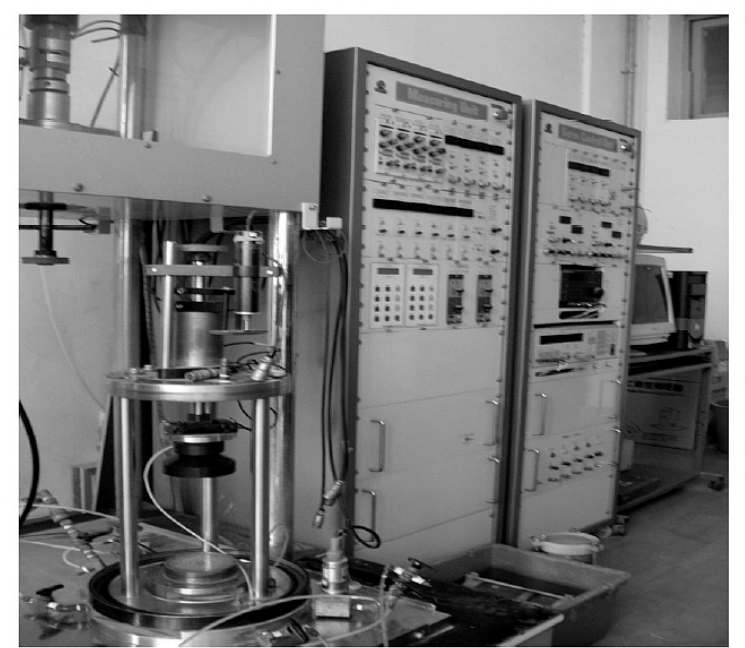

Fig. 3. Static-dynamic dual-purpose triaxial test apparatus.

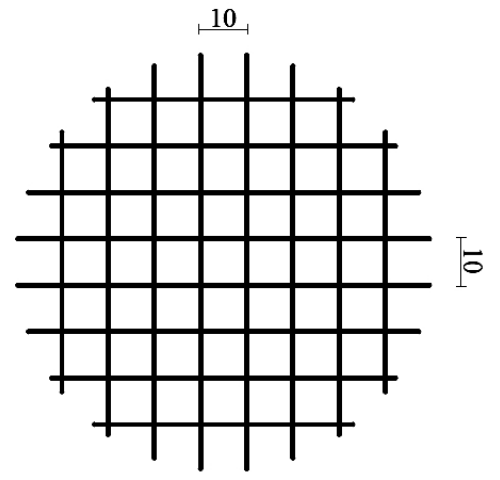

Fig. 2. Reinforcement mesh geometry (in $\mathrm{mm})$.

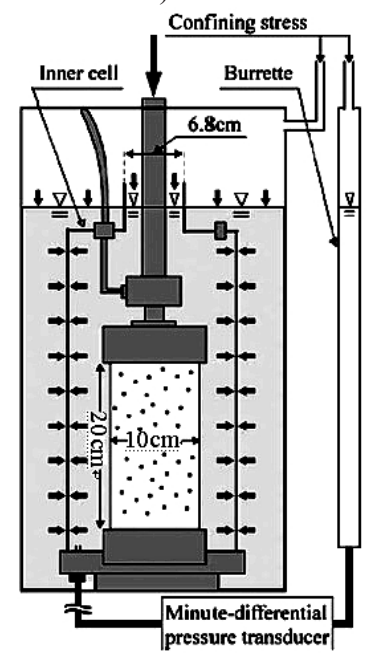

Fig. 4. Large triaxial cell.

induced large-scale ground deformation. In the test, the triaxial cell was submerged to the level of a small-diameter mouth of the inner cell as indicated in Fig. 4.

The cylindrical specimens $(100 \times 200 \mathrm{~mm})$ were used in this study. The specimen preparation is critical for these laboratory tests: their density and degree of saturation had to be carefully adjusted. A $101 \mathrm{~mm}$-diameter split mold was used to prepare the specimens. 
The mold was equipped with a vacuum fitting on the side to provide air removal from the space between the mold and latex membrane liner. Specimens were produced in four lifts using a funnel to pour the material and a tamp to achieve its compaction. To ensure a proper compaction, each layer was exposed to approximately 50 impacts with the tamp. The desired density was achieved by the retrospective calculation of the material weight from the known volume of the specimen mold and via the tamping intensity adjustment by the trial-and-error technique.

Multiple series of dynamic triaxial tests were conducted to study the effects of various parameters, including confining pressures, initial stress ratio $\left(K_{c}=\sigma_{1} / \sigma_{3}\right)$, dynamic stress and reinforcement pattern. The procedures for specimen preparation and testing were standardized to achieve their repeatability. The regularly excited drained triaxial test was performed using a sine waveform. After conditioning, the cyclic loading with 25 cycles was performed at a frequency of $0.1 \mathrm{~Hz}$. A summary of test parameters is as follows:

(i) three different reinforced specimens (Fig. 5);

(ii) three confining pressures $\sigma_{3}(0.2,0.4$, and $0.6 \mathrm{MPa})$;

(iii) two initial stress ratios $K_{c}(1.0$ and 2.0$)$;

(iv) two different dynamic stresses $\sigma_{d}\left(0.4 \sigma_{3}\right.$ and $\left.0.8 \sigma_{3}\right)$.

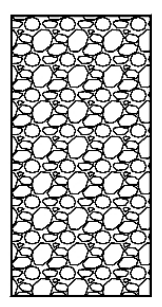

a

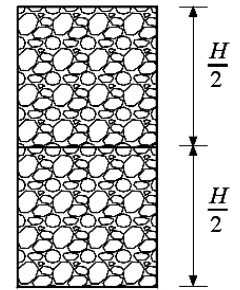

b

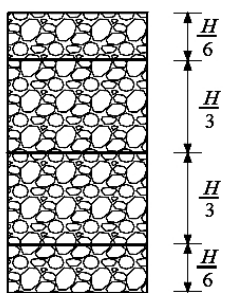

c

Fig. 5. Scheme of the reinforced specimen: (a) $N_{r}=0$; (b) $N_{r}=1$; (c) $N_{r}=3$.

\section{Results and Discussion.}

Initial Stress Effect . Figure 6 shows variations of the residual axial and volume strains versus the initial stress for the specimens at the initial stress ratios of 1 and 2 . It is seen that the residual strain significantly increases with confining pressures, and also increases with the initial stress ratio level. Noteworthy is that a smaller difference in the residual axial strain values is observed for lower $(0.2 \mathrm{MPa})$ confining pressures at different initial stress ratios and reinforcement patterns. For specimens subjected to the triaxial test with $K_{c}=1$ and $N_{r}=3$, the increase in $\sigma_{3}$ from 0.2 to $0.6 \mathrm{MPa}$ provides the increase in the residual axial and volume strains by approximately 379 and $337 \%$, respectively. This implies that the reinforcement-filter material interaction under lower confining pressures is no more pronounced than that under higher ones.

Cyclic Loading Effect. The dynamic triaxial test results as variations of the residual axial/volume deformation versus $N$ for the tested specimens are shown in Fig. 7. It can be seen that the residual axial/volume strains increase with $N$ and the rate of such increase is very substantial at the early stages of compression. The only exception is the case of $K_{c}=1$ and $\sigma_{d}=0.8 \sigma_{3}$, where this increase rate is low at the early stages of compression, due to the fact that specimen loading occurred under a higher dynamic stress. It is clear that, under the isotropic consolidation conditions $\left(K_{c}=1\right)$, the residual axial/volume strains for $\sigma_{d}=0.4 \sigma_{3}$ are larger than those at $\sigma_{d}=0.8 \sigma_{3}$.

For specimens tested under the anisotropic consolidation conditions $\left(K_{c}=2\right)$, in contrast to isotropic ones, the residual strain increases not only with $N$, but with $\sigma_{d}$ as well. When the number of reinforcements $\left(N_{r}\right)$ was increased from 0 to 3 , there was only a 


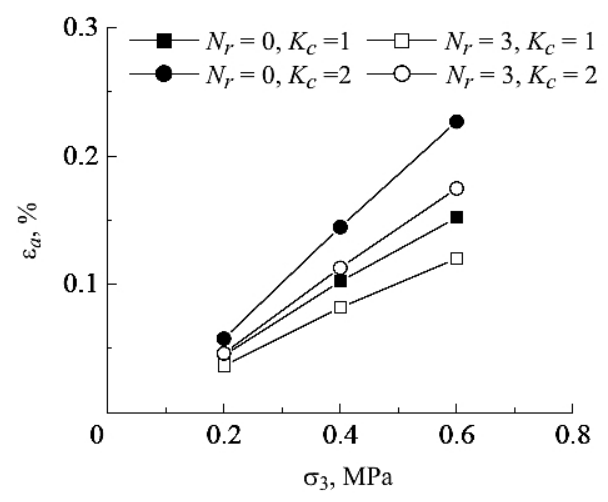

a

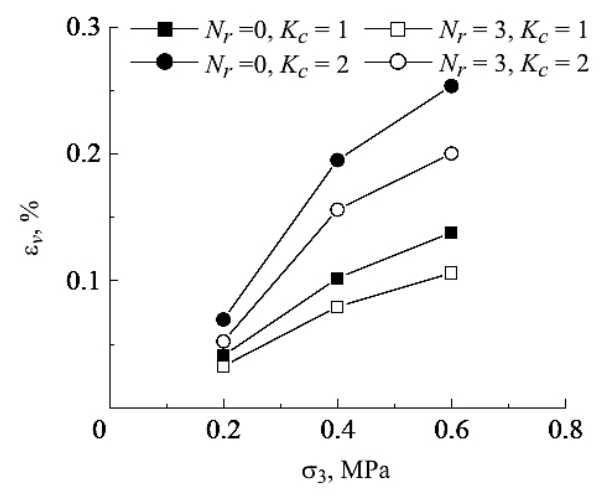

b

Fig. 6. The initial stress effect on the residual axial (a) and residual volume (b) strains.

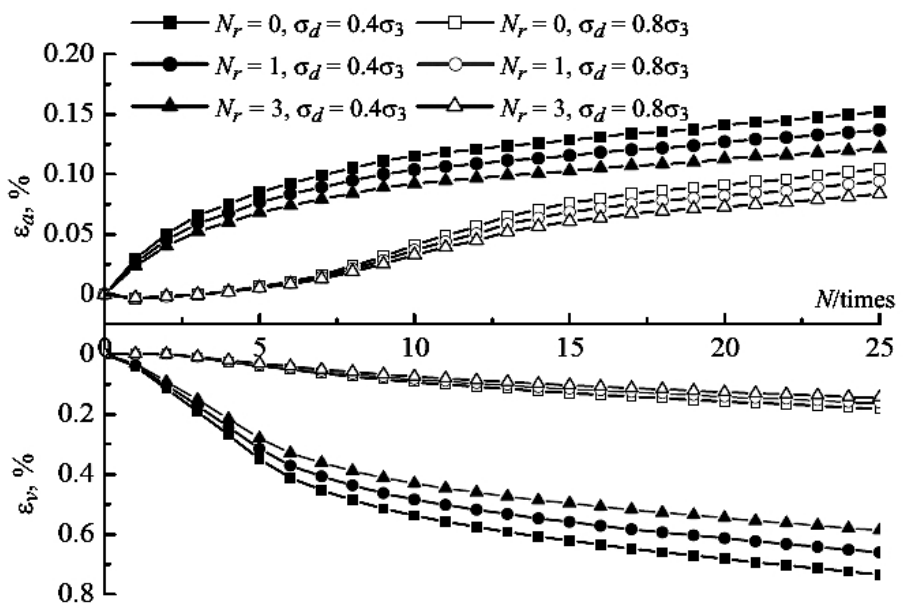

a

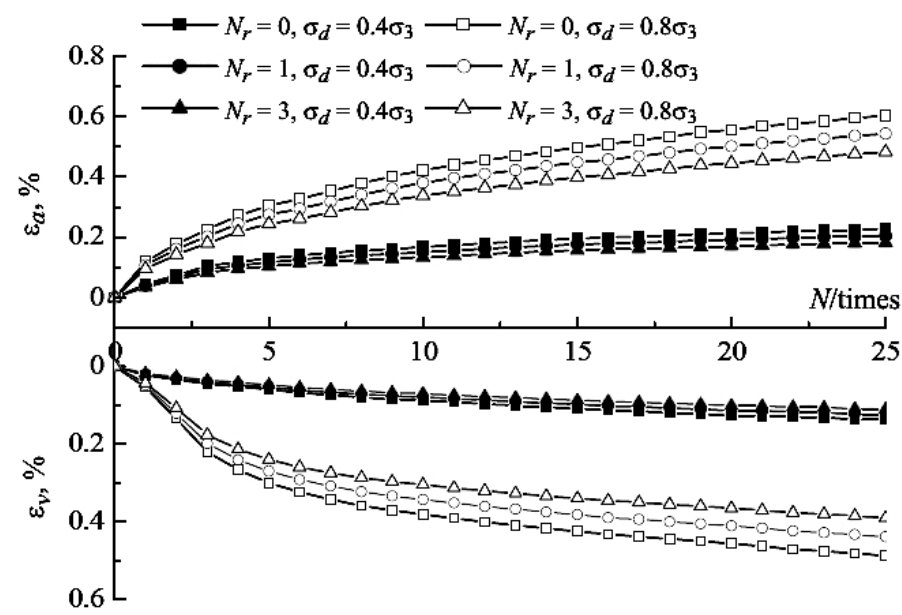

$\mathrm{b}$

Fig. 7. The cyclic loading effect on residual strain at $\sigma_{3}=0.6 \mathrm{MPa}$ for $K_{c}=1$ (a) and $K_{c}=2$ (b). 
marginal increase in the residual strain. The residual axial/volume strain $\left(\sigma_{d}=0.4 \sigma_{3}\right)$ remained independent of $N$, when $N$ exceeded 5.

Effect of Reinforcement Pattern. Figure 7 also shows the variations of residual strains versus reinforcement pattern. It can be seen that the residual strain trend is consistent, irrespectively of the reinforcement presence or absence. It is apparent that the residual strain of reinforced filter material is much higher than that of unreinforced one, while the reinforcement effect at $N_{r}=3$ is more pronounced than that at $N_{r}=1$. For specimens tested at $K_{c}=1$ and $\sigma_{3}=0.2 \mathrm{MPa}$, reduction of $N_{r}$ from 3 to 0 resulted in the increase in the residual axial and volume strains by approximately 122 and $125 \%$, respectively. It is evident that the strain behavior improvement of the filter material is due to the reinforcing layers.

Mechanism of Reinforcement. From the test results of the filter materials, it is found that the residual strain depends on the reinforcement spacing and loading conditions. The residual stresses are induced by compaction or preloading in the base course, while stiffness of granular base materials is also increased due to loading. Geosynthetics is widely used in the geotechnical engineering for the mechanical stabilization purpose. This is a typical property of grid inclusions, occurring when filter materials are compacted on the top of grid inclusions, letting the particles partially project through the grid inclusion apertures to lock them. Lin et al. [8] studied the transfer of stress between sand and grid inclusions and identified the important mechanisms of sand and grid inclusion interactions through pullout tests. The intrinsic factors, which control and change the mechanism of the interface properties, are: friction-induced cohesion, occlusive force, and passive resistance. Therefore, reinforcements restrain the lateral spreading of the filter base layer and through interlocking develop a relatively stiffer layer-surrounding reinforcements.

Evaluation of Residual Deformation. The residual strain evaluation techniques are mainly based on the Shen Zhujiang, the Taniguchi, and the IWHR models. According to the Shen Zhujiang model, which is widely applied in the aseismic design of filter dams, the residual strain can be generated via the material loading with a certain set of parameters, including different vibration times, cyclic strain and stress levels. To evaluate the effects of the grid inclusions on the residual strain of reinforced filter materials, the modified Shen Zhujiang model was proposed in [9], as follows:

$$
\begin{gathered}
\varepsilon_{v r}=c_{v r} \log (1+N), \\
\gamma_{r}=c_{d r} \log (1+N), \\
c_{v r}=c_{1}\left(\gamma_{d}\right)^{c_{2}} \exp \left(-c_{3} S_{l}^{2}\right), \\
c_{d r}=c_{4}\left(\gamma_{d}\right)^{c_{5}} S_{l},
\end{gathered}
$$

where $\varepsilon_{v r}$ is residual volume strain, $\gamma_{r}$ is residual shear strain, $\gamma_{d}$ is amplitude of dynamic shear strain, $S_{l}$ is stress level, $N$ is the number of loading cycles, and $c_{1}, c_{2}$, $c_{3}, c_{4}$, and $c_{5}$ are the test parameters. According to the above results, the effect of stress level on $c_{v r}$ can be neglected $\left(c_{3}=0\right)$.

To specify the above relations, the average value of residual strain is selected. For different reinforcement spacings, the curves of residual shear strain $\left(\gamma_{r}\right)$ and residual volume strain $\left(\varepsilon_{v r}\right)$ versus the number of cycles are constructed (Fig. 8). These plots indicate that a close linear correlation exists between the residual shear/volume strain and the parameter $\log (1+N)$ in the Cartesian coordinate system. The dynamic residual strain parameters are summarized in Table 2. Parameters $c_{1}$ and $c_{4}$ exhibit an increase with $N_{r}$. 
T a b 1 e 2

Residual Strain Parameters of Reinforced Materials

\begin{tabular}{||c|c|c|c|c|c||}
\hline $\begin{array}{c}\text { Reinforcment } \\
\text { type }\end{array}$ & $c_{1}$ & $c_{2}$ & $c_{3}$ & $c_{4}$ & $c_{5}$ \\
\hline$N_{r}=0$ & 0.38 & 0.79 & 0 & 4.56 & 1.05 \\
\hline$N_{r}=1$ & 0.34 & 0.86 & 0 & 3.47 & 1.07 \\
\hline$N_{r}=3$ & 0.29 & 0.89 & 0 & 3.04 & 1.12 \\
\hline
\end{tabular}
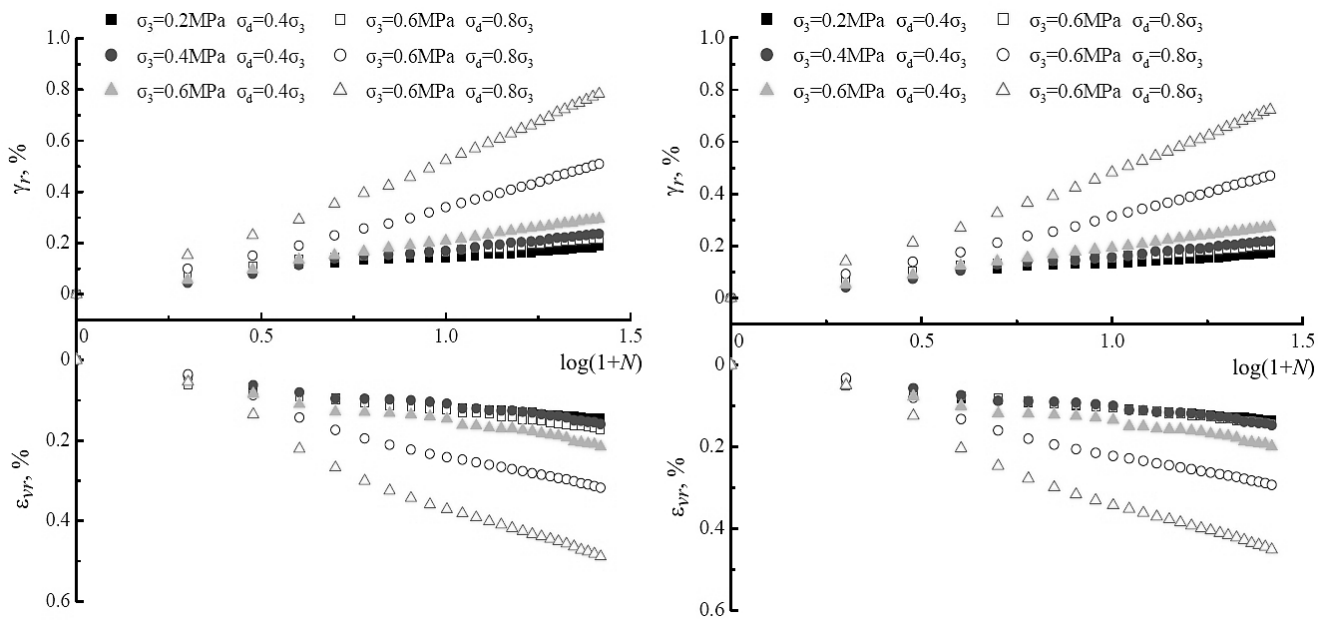

a

b

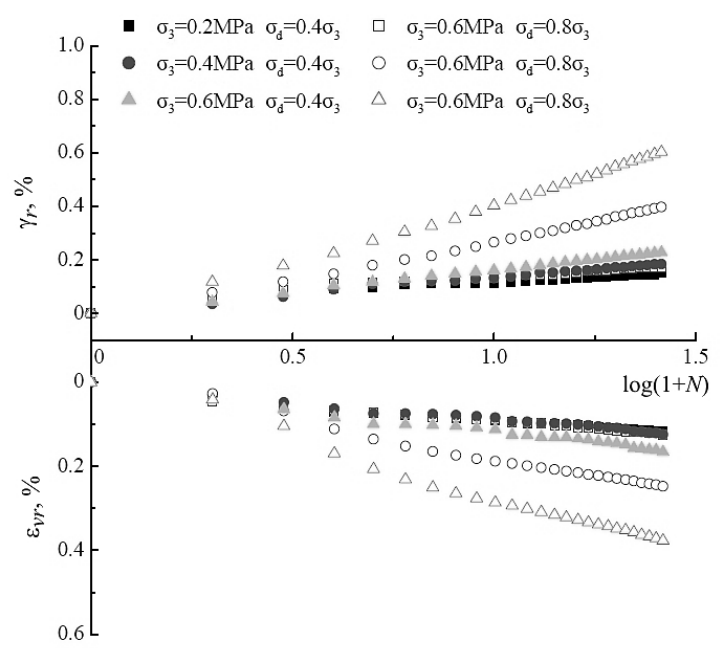

c

Fig. 8. Residual strain vs. $\log (1+N)$ : (a) $N_{r}=0$; (b) $N_{r}=1$; (c) $N_{r}=3$.

Conclusions. Based on the results obtained on residual strains in the reinforced and unreinforced filter materials, the following conclusions can be drawn:

1. The cyclic loading-induced residual strains of unreinforced $\left(N_{r}=0\right)$ exhibit a consistent trend: for the preset values of the initial and dynamic stresses, the residual strain increases with the number of cycles. 
2. Due to the existence of reinforcement, the specimen elastic modulus and stiffness are increased, the specimen lateral expansion is limited to some extent, and the residual strain is also reduced.

3. The results obtained confirm that it is feasible to improve the filter dam seismic characteristics by reinforcement. In this study, only the effect of reinforcement spacing and loading conditions are investigated, and further research on other factors is required.

Acknowledgments. This study is supported by the National Natural Science Foundation of China (NSFC) under Grant No. 51209132, and Innovation Program of Shanghai University (sdcx2012044). These supports are gratefully acknowledged.

1. S. M. Haeri, R. Noorzad, and A. M. Oskoorouchi, "Effect of geotextile reinforcement on the mechanical behavior of sand," Geotext. Geomembr., 18, No. 6, 385-402 (2000).

2. C. Zhao and Y. T. Zhou, "Experimental study on polymer geogrid reinforced crushed gravel by large-scale triaxial test," Rock Soil Mech., 22, No. 4, 419-422 (2001).

3. Z. H. Yu, H. W. Wei, and Y. S. Zou, "Characteristics of shear strength and deformation of reinforced red sand silty clay with geosynthetics," Chinese J. Rock Mech. Eng., 24, No. 15, 2770-2779 (2005).

4. J. H. Wu, D. Q. Wang, and H. Chen, "Study on geosynthetic reinforced sand by triaxial compression test," Chinese J. Geotech. Eng., 22, No. 2, 199-204 (2000).

5. N. R. Krishnaswamy and N. T. Isaac, "Liquefaction potential of reinforced sand," Geotext. Geomembr., 13, No. 1, 23-41 (1994).

6. D. Vercueil, P. Biller, and D. Cordary, "Study of the liquefaction resistance of a saturated sand reinforced with geosynthetics," Soil Dyn. Earthq. Eng., 16, No. 7-8, 417-425 (1997).

7. A. Boominathan and S. Hari, "Liquefaction strength of fly ash reinforced with randomly distributed fibers," Soil. Dyn. Earthq. Eng., 22, No. 9-12, 1027-1033 (2002).

8. Y. L. Lin, B. Zhang, M. X. Zhang, and G. F. Zhao, "Micro and meso-mechanism study of interface behavior of earth reinforced with denti-inclusions," Rock Soil Mech., 34, No. 10, 2863-2868 (2013).

9. D. G. Zou, F. W. Meng, X. J. Kong, et al., "Resudual deformation behavior of rock-fill materials," Chinese J. Geotech. Eng., 30, No. 6, 807-812 (2008).

Received 20. 10. 2014 